\title{
Deficient Activity of Mitochondrial Flavine Adenine Dinucleotide-Linked Glycerophosphate Dehydrogenase in Pancreatic Islet Beta Cells as a Determinant of Non-Insulin- Dependent Diabetes Mellitus
}

\author{
Willy J. Malaisse
}

\begin{abstract}
Extensive experimental investigations in animal models of diabetes mellitus have led to the proposal that a deficient activity of mitochondrial flavine adenine dinucleotide (FAD)-linked glycerophosphate dehydrogenase represents a far-from-uncommon, albeit not invariable, determinant of pancreatic islet B-cell insulin secretory dysfunction. The major aim of the present review is to summarize the results of these investigations and, hence, to encourage further work on the prevalence of this enzymatic defect in the islet B cell of human subjects, especially non-insulin-dependent diabetic patients.
\end{abstract}

Keywords: Pancreatic islet beta cells; FAD-linked glycerophosphate dehydrogenase; Non-insulin-dependent diabetes mellitus

\section{Introduction}

In non-insulin-dependent (type 2) diabetes mellitus (NIDDM), the insulin-producing pancreatic islet $\mathrm{B}$ cells often display a preferential impairment of their secretory response to Dglucose, as distinct from other nutrient or non-nutrient secretagogues. Several candidates were proposed to account for such a preferential secretory defect. Five of these candidates, reported to as a $G$ quintet include 1) underexpression of the Glut-2 carrier gene, causing a delayed or incomplete equilibration of D-glucose concentration across the B-cell plasma membrane, 2) glucokinase mutation, resulting in an impaired phosphorylation of D-glucose in the B-cell, 3) glucose6-phosphatase hyperactivity, leading to operation of a futile ATP-wasting cycle between glucose and glucose-6-phosphate, 4) glycogen accumulation, which may be responsible for the secondary phenomenon of so-called B-cell glucotoxicity, and 5) B-cell mitochondrial flavine adenine dinucleotide (FAD)-

Manuscript submitted March 9, 2018, accepted March 19, 2018

Department of Biochemistry, Universite Libre de Bruxelles, 808 Route de Lennik, B-1070 Brussels, Belgium. Email: malaise@ulb.ac.be

doi: https://doi.org/10.14740/jem496w linked glycerophosphate dehydrogenase (m-GDH) deficiency [1]. One of the major aims of the present review is to draw attention to preclinical findings in support of the latter defect in several animal models of NIDDM.

Incidentally, the fourth of the above-mentioned candidates, which is currently held responsible of two frequent anomalies of the B-cell secretory response to glucose in NIDDM subjects, i.e. an early paradoxical decrease in insulinemia in response to the intravenous administration of glucose [2] and the alteration of the anomeric specificity of glucose-induced insulin release [3], should be considered as the consequence, rather than cause, of hyperglycemia in these subjects. Hence, a sixth candidate could be mentioned, i.e. the non-enzymatic glycation of B-cell proteins possibly leading to a perturbation of the catalytic behavior of selected enzyme(s) or alteration of the functional capacity of effector protein(s) involved in the process of glucose-induced insulin release by the pancreatic islet $\mathrm{B}$ cell [4].

Briefly, the background information which led to the identification of an FAD-linked glycerophosphate dehydrogenase anomaly in experimental models of NIDDM, refers to the fact that, in normal pancreatic islet B cells, a rise in the extracellular concentration of glucose provokes a preferential stimulation of aerobic, as distinct from anaerobic, glycolysis [5-7]. This metabolic situation coincides with a glucose-induced acceleration of substrate circulation in the glycerol phosphate shuttle, taken as the ratio between the production of ${ }^{3} \mathrm{HOH}$ and the specific radioactivity of $\mathrm{L}-\left[2-{ }^{3} \mathrm{H}\right]$ glycerophosphate in islets exposed to $\left[2-{ }^{3} \mathrm{H}\right]$ glycerol [8].

The preferential stimulation of mitochondrial events relative to total glycolytic flux coincides with a preferential stimulation of pyruvate oxidative decarboxylation and, hence, optimizes the yield of ATP generated by the catabolism of Dglucose. An accelerated generation of ATP and an increase in its cytosolic concentration are currently considered as the key mechanism coupling the metabolism of nutrients to more distal events in the insulin secretory sequence, especially the closure of ATP-responsive $\mathrm{K}^{+}$channels and subsequent gating of voltage-sensitive $\mathrm{Ca}^{2+}$ channels. The preferential stimulation by glucose of oxidative glycolysis coincides with and is attributable to activation by $\mathrm{Ca}^{2+}$ of the m-GDH, which plays a key role in controlling circulation in the glycerol phosphate shuttle for the transfer of reducing equivalents from the cytosol into 
the mitochondria. The specific activity of m-GDH, expressed relative to protein content, is higher in pancreatic islets than in other organs so far examined for such a purpose. In the islets, the enzyme is virtually confined to insulin-producing cells, as distinct from non-B islet cells [8].

\section{Preclinical Animal Investigations}

The pilot observation of a deficiency in pancreatic islet mGDH activity was made in adult rats which had been injected with streptozotocin (STZ) during the neonatal period. Investigations on the metabolism of D-glucose in intact islets prepared from these rats first documented an abnormally low ratio between oxidative and total glycolysis [9]. Measurements made in isolated islet mitochondria or islet homogenates then revealed a severe deficiency of the activity of m-GDH [10]. This coincided with an impaired circulation through the glycerol phosphate shuttle in glucose-stimulated islets, as judged from either the hexose-induced increase in ${ }^{3} \mathrm{HOH}$ generation from $\left[2-{ }^{3} \mathrm{H}\right]$ glycerol or absolute value for the conversion of $\left[2-{ }^{3} \mathrm{H}\right]$ glycerol to ${ }^{3} \mathrm{HOH}[11]$.

More precisely, it was first proposed that the relative cationic and secretory unresponsiveness to glucose in islets from these NIDDM rats probably reflected alteration in the islet mitochondrial function [12]. Attention was then drawn to the fact that the diabetic status of the adult rats injected with STZ during the neonatal period could not be merely ascribed to a process of glucotoxicity, involving a long-term damage of key mitochondrial dehydrogenases in the pancreatic B cells and, possibly, their precursor cells [13]. Metabolic data then documented an impairment of the glycerol phosphate shuttle in the islets from rats with diabetes induced by neonatal STZ [9]. Such an NIDDM could not be attributed to either an anomaly of hexose transport into the islet cells or any change in pancreatic islet glucose-6-phosphatase activity. However, the specific activity of $\mathrm{m}-\mathrm{GDH}$ was found to be decreased down to about one-third of its control value [10].

Further investigations documented that, whilst STZ (1.0 - $2.0 \mathrm{mM}$ ) failed to exert any immediate in vitro effect upon m-GDH activity, in rat pancreatic islets, the specific activity of the enzyme in islet homogenates was lowered, within $24 \mathrm{~h}$ after intravenous administration of STZ to adult rats. A few days after such an administration, the severity of the islet enzymatic defect paralleled that of the diabetic state. Yet, a decreased enzymatic activity was also observed in islets from virtually normoglycemic animals examined 2 - 3 weeks after STZ administration [14, 15].

A deficient activity of FAD-linked glycerophosphate dehydrogenase was also observed in pancreatic islet extracts of rats with hereditary NIDDM, i.e. Goto-Kakizaki (GK) rats. The mitochondrial $\mathrm{m}-\mathrm{GDH}$ activity, as measured by a radioisotopic or colorimetric procedure, only represented $30-40 \%$ of that found in control rats. The decrease in enzymic activity was not attributable to any sizeable change in either DNA content or the relative contribution of insulin-producing beta cells to total islet mass. It contrasted with a normal activity of other mitochondrial dehydrogenases and hexokinase isoenzymes. It coincided, however, with an increased activity of glutamatepyruvate transaminase (GPT), as already observed in adult rats injected with STZ during the neonatal period. The decreased activity of islet FAD-linked glycerophosphate dehydrogenase also contrasted with an increased activity of the same enzyme in the liver of GK, as compared to control rats. In the light of these findings and metabolic data recently collected at that time in intact islets of GK rats, it was proposed that a deficiency of beta-cell FAD-linked glycerophosphate dehydrogenase, the key enzyme of the glycerol phosphate shuttle, may represent a cause of inherited NIDDM [16].

Four sets of investigations aimed at comparing the situations found in pancreatic islets of two rat models of either inherited or acquired type 2 (non-insulin-dependent) diabetes mellitus. In islets from both adult rats injected with STZ during the neonatal period and spontaneously diabetic rats obtained by repeated selected breedings (GK rats), the ratio between D$\left[3,4-{ }^{14} \mathrm{C}\right]$ glucose oxidation and $\mathrm{D}-\left[5-{ }^{3} \mathrm{H}\right]$ glucose conversion to ${ }^{3} \mathrm{HOH}$ was $25 \%$ lower than in islets from control rats, indicating an impaired contribution of oxidative to total glycolysis. No primary defect in the Krebs cycle was found in the islets of diabetic rats, as judged from the ratio between $\mathrm{D}-\left[2-{ }^{14} \mathrm{C}\right]$ glucose or D-[6- $\left.{ }^{14} \mathrm{C}\right]$ glucose and D- $\left[3,4-{ }^{14} \mathrm{C}\right]$ glucose oxidation. It was proposed, therefore, that a preferential alteration of oxidative glycolysis in the pancreatic beta cell may contribute to the impairment of glucose-induced insulin release not only in a cytotoxic but also in a spontaneous model of NIDDM [17].

The "Metabolic, ionic and secretory response to D-glucose in islets from rats with acquired or inherited non-insulindependent diabetes" was the title of the second article. The body weight, plasma glucose and insulin concentrations, insulinogenic index, islet insulin and protein content of rats injected with STZ during the neonatal period (STZ rats) and of GK rats were compared to the values found in control rats with a mean age virtually identical to that of the diabetic animals. Whilst the ATP/ADP ratio found in islets from control rats incubated for $60 \mathrm{~min}$ at 2.8, 8.3 and 16.7 $\mathrm{mM} \mathrm{D}$-glucose progressively increased at these hexose concentrations from $2.13 \pm$ 0.18 to $2.48 \pm 0.20$ and $2.75 \pm 0.19$, it failed to do so in the STZ rats, averaging at the three concentrations of D-glucose $2.07 \pm$ $0.27,2.06 \pm 0.12$ and $2.14 \pm 0.18$ and progressively decreased from $3.05 \pm 0.56$ to $2.21 \pm 0.18$ and $2.18 \pm 0.20$ in the GK rats. In perifused islets, both the basal insulin output measured in the presence of $2.8 \mathrm{mM}$ D-glucose and the increment in insulin output attributable to a rise in D-glucose concentration up to $8.3 \mathrm{mM}$ were also higher in control than in either STZ or GK rats. Under the same experimental conditions, the rise in hexose concentration decreased $\left[2-{ }^{3} \mathrm{H}\right]$ adenosine fractional outflow from prelabelled control islets, but failed to do so in the islets prepared from either STZ or GK rats. The phosphate flush evoked by the rise in glucose concentration was also more marked in the control islets than that found in the islets from diabetic rats. In islets prelabelled with ${ }^{86} \mathrm{Rb}$, the same rise in hexose concentrations during perifusion decreased ${ }^{86} \mathrm{Rb}$ fractional outflow rate by $1.35 \pm 0.26 \%$ per min in control rats, as distinct from only $0.99 \pm 0.13 \%$ and $0.60 \pm 0.22 \%$ per min in STZ and GK rats, respectively. The last series of experiments primarily aimed at exploring whether exogenous pyruvic acid $(5.0 \mathrm{mM})$, acting as a hydrogen acceptor, would be able to im- 
prove the glycolytic response of pancreatic islets to a rise in extracellular D-glucose concentration from 2.8 to $16.7 \mathrm{mM}$. The metabolic variables under consideration included D-[5$\left.{ }^{3} \mathrm{H}\right]$ glucose utilization, D- $\left[2-{ }^{14} \mathrm{C}\right]$ glucose oxidation and conversion to either acidic metabolites or amino acids. Both the oxidation of $\left[2-{ }^{13} \mathrm{C}\right]$ pyruvate and its conversion to amino acids were also measured in islets exposed to either 2.8 or $16.7 \mathrm{mM}$ $\mathrm{D}$-glucose. The ratio in either $\mathrm{D}-\left[5-{ }^{3} \mathrm{H}\right]$ glucose utilization or D- $\left[2-{ }^{14} \mathrm{C}\right]$ glucose oxidation of high/low hexose concentration, as well as the paired ratio between D-[2- $\left.{ }^{14} \mathrm{C}\right]$ glucose oxidation and $\mathrm{D}-\left[5-{ }^{3} \mathrm{H}\right]$ glucose utilization in islets incubated at a high concentration of the hexose, were also lower in STZ and GK rats than in control rats. Such was not the case, however for either $\left[2-{ }^{14} \mathrm{C}\right]$ pyruvate oxidation or conversion to amino acids, whether in the presence of either 2.8 or $16.7 \mathrm{mM}$ D-glucose, the mean values for the two variables of $\left[2-{ }^{14} \mathrm{C}\right]$ pyruvate metabolism being, both at 2.8 and $16.7 \mathrm{mM} \mathrm{D}$-glucose, invariably higher in diabetic rats than in control animals. It was proposed, therefore, that in both STZ and GK rats, the B-cell secretory defect was primarily attributable to an anomaly in oxidative glycolysis. In islets exposed to a high concentration of D-glucose, the metabolic deficiency resulted in impaired ATP generation, altered closing of ATP-responsive $\mathrm{K}^{+}$channels and, hence, diminished insulin output [18].

A third study documented, in both hereditarily diabetic GK rats and animals injected with STZ during the neonatal period, a pronounced decrease of immunoreactive m-GDH, as assessed by Western blotting of pancreatic islet extracts, when compared to results obtained in islets from control rats. By contrast, the islet glucokinase protein content was either unaffected (GK rats) or much less severely decreased than that of $\mathrm{m}-\mathrm{GDH}$ (STZ rats). These findings indicated that the impaired activity of m-GDH previously documented in islet homogenates from diabetic rats coincides with a decreased content of this enzyme in the endocrine pancreas [19].

In the last of these three sets of investigations, attention was drawn to the contrasting behavior of pancreatic islets from old rats in the two models of NIDDM under consideration. Thus, the secretory behavior of pancreatic islets from 20 week old rats that had been injected with STZ during the neonatal period (STZ rats) or GK rats was compared to that of islets from control animals of the same age. In the STZ rats, the insulin content of the islets was about one-third lower than in the control animals, but the ratio between insulin output and content was close to normal in islets stimulated by D-glucose, the monomethyl ester of succinic acid (SAM), the meglitinide analogue $\mathrm{A}-4166, \mathrm{Ba}^{2+}$ and theophylline, these secretagogues being tested either alone or in combination. The insulin content of the islets from GK rats was decreased to the same extent as in STZ rats. However, in the GK rats, the secretory behavior was severely disturbed with an abnormally high basal insulin output, a paradoxical inhibition of insulin release by either Dglucose or SAM, a failure of $\mathrm{Ba}^{2+}$ to stimulate insulin release from $\mathrm{Ca}^{2+}$-deprived islets and an impaired responsiveness to the combination of SAM and A-4166. In the GK rats, the high basal insulin output and its paradoxical inhibition by D-glucose could conceivably be attributable to glycogen deposition in the islets of these frankly hyperglycemic rats. Three findings argue, however, against this interpretation. First, in a previous study, we were unable to detect any obvious accumulation of glycogen in the B cell of GK rats. Second, theophylline failed to enhance insulin release from islets of GK rats incubated in the absence of glucose but at normal extracellular $\mathrm{Ca}^{2+}$ concentration, whereas the phosphodiesterase inhibitor otherwise stimulates insulin release, under the same experimental conditions, from glycogen-rich islets. Last, the hypothetical occurrence of a high glycogenolytic flux in glucose-deprived islets from GK rats and its inhibition by D-glucose cannot account for the inhibition of basal insulin release by SAM, as indeed observed in such islets. Thus, in hyperglycemic animal models characterized by a large accumulation of glycogen in the B cell, only D-glucose causes a paradoxical inhibition of insulin release, whilst non-glucidic nutrients, such as 2-ketoisocaproate, further enhance the already elevated basal insulin output. An alternative explanation for the findings made in islets from GK rats could consist in a perturbation of intracellular $\mathrm{Ca}^{2+}$ homeostasis, possibly linked to insufficient ATP generation. Such a situation could also account for the failure of $\mathrm{Ba}^{2+}$ to stimulate insulin release from GK rat islets at least in the absence of theophylline. Likewise, the working hypothesis of a perturbed generation of ATP in islets from GK rats may also account for their poor responsiveness to the combination of SAM and A-4166, since the insulinotropic action of the meglitinide analog is tightly linked to the nutritional status of the $\mathrm{B}$ cell. In conclusion, therefore, the above-mentioned findings suggested that the perturbation of B-cell function in GK rats may involve metabolic and ionic determinants that are not operative in islets from STZ rats. This proposal was considered consistent with the view that the diabetic syndrome in GK rats results from a multifactorial genetic defect. In other words, these findings suggested that GK rats, but not STZ rats, suffer from a severe perturbation of B-cell fuel balance, this anomaly persisting in aged animals [20].

When cultured mouse pancreatic islets were exposed for $30 \mathrm{~min}$ to STZ $(1.8 \mathrm{mM})$ and then maintained for 7 days in culture medium, they displayed a decreased secretory response to D-glucose and an impairment of both FAD-linked glycerophosphate dehydrogenase and NAD-dependent 2-ketoglutarate dehydrogenase specific activities, with little change in either NAD-linked glycerophosphate dehydrogenase or glutamate dehydrogenase (GIDH) activity. The enzyme defect was not reproduced by prolonged exposure of mouse islets to a high concentration of D-glucose $(28 \mathrm{mM})$. The STZ-induced suppression of $\mathrm{m}-\mathrm{GDH}$ activity was proposed to explain the preferential alteration of the B-cell metabolic and secretory responses to D-glucose, as previously observed in islets of adult rats injected with STZ during the neonatal period [21].

A further study was devoted to the effect of STZ upon $\mathrm{m}-\mathrm{GDH}$ activity and insulin release in purified rat pancreatic insulin-producing B cells. Freshly isolated B cells displayed a 12-fold higher activity of FAD-linked glycerophosphate dehydrogenase than other islet endocrine cells, results being expressed relative to cell DNA content. The purified B cells were exposed for $30 \mathrm{~min}$ to $2 \mathrm{mM} \mathrm{STZ}$ and subsequently cultured for 2 days in the absence or presence of $2 \mathrm{mM}$ nicotinamide. STZ decreased by $54 \%$ the number of B cells and, in surviving cells, lowered by $75 \%$ the activity of m-GDH, whilst failing to affect that of GIDH. This coincided with a $42-51 \%$ 
reduction of insulin secretion during the 2-day culture period, when expressed relative to either the DNA or hormonal content of surviving cells. After exposure to STZ, the presence of nicotinamide in the culture medium reduced cell death by $44 \%$ and also reduced the deleterious effects of STZ upon both the enzymic and secretory activities of surviving cells. These findings indicated that the decreased activity of m-GDH previously documented in pancreatic islets from STZ-injected rats, as well as the protective effect of nicotinamide thereupon, are not attributable solely to change in the number of B cells but also to an altered enzymatic activity of surviving B cells. The latter anomaly may account, in part at least, for an impaired B-cell secretory response to D-glucose [22].

The intrinsic properties of FAD-linked glycerophosphate dehydrogenase were eventually compared in islets from normal and STZ-induced diabetic rats. As expected, the activity of $\mathrm{m}-\mathrm{GDH}$, as measured by either a radioisotopic or colorimetric procedure, was severely decreased in the rats injected intravenously with STZ (40 mg/kg body wt.) 4 days before sacrifice. The intrinsic properties of the enzyme were preserved, however, as judged from the affinity for L-glycerol3-phosphate, the ratio in reaction velocity using either FAD or iodinitrotetrazolium as electron acceptor and the activation of the enzyme by $\mathrm{Ca}^{2+}$. When the same kinetic parameters were compared in islet, liver and spleen homogenates from normal rats, significant differences were observed, however, between these three tissues, suggesting the possible existence of distinct isoenzymes [23].

The activity of m-GDH, as well as that of glutamate decarboxylase (GAD), glutamate-oxaloacetate transaminase, GPT, GIDH and 2-ketoglutarate dehydrogenase, was significantly lower in tumoral islet cells of the RINm5F cells than in normal islet cells, whilst the activity of hexokinase and lactate dehydrogenase was higher in tumoral than normal islet cells. These findings were considered as consistent with the high rates of glycolysis and protein synthesis seen in tumoral islet cells compared to normal islet cells [24].

The major aim of a further investigation was to explore whether splenic lymphocytes from either rats injected with STZ during the neonatal period or GK rats also display altered activity of $\mathrm{m}-\mathrm{GDH}$. The assay of $\mathrm{m}-\mathrm{GDH}$ was performed by either a colorimetric procedure based on the generation of iodoformazan from 2-(4-iodophenyl)-3-(4-nitrophenyl)-5-phenylate tetrazolium chloride or a radioisotopic technique based on the generation of ${ }^{3} \mathrm{HOH}$ from L- $\left[2-{ }^{3} \mathrm{H}\right]$ glycerol-3-phosphate. The results indicated that no significant difference between control rats and either STZ or GK rats was observed in terms of the protein content of splenocytes and the activity of m-GDH, GIDH, glutamate-oxalacetate transaminase (GOT) or glutamate pyruvate transaminase in splenocyte homogenates. As expected from the intrinsic properties of m-GDH, the velocity of the reaction catalyzed by the enzyme was under the present experimental conditions, much higher in the colorimetric than radioisotopic assay procedure. Incidentally, such a difference could not be blamed on the difference in either $\mathrm{pH}$ or ionic composition of the buffered solution used in the colorimetric $(\mathrm{pH} 8)$ or radioisotopic $(\mathrm{pH} 7.2)$ procedure. Indeed, the paired ratio in reaction velocity at $\mathrm{pH} 7.2 / \mathrm{pH} 8$, as measured in splenocytes of control rats, averaged $88.8 \pm 0.7 \%$ in the colorimetric assay and $92.7 \pm 1.2 \%$ in the radioisotopic procedure. As in other cell types, $\mathrm{Ca}^{2+}$ increased the affinity of m-GDH for L-glycerol-3-phosphate. The normal activity of mGDH in the splenocytes of STZ rats is not surprising, since in these animals, the islet enzymatic effect results from a primary cytotoxic aggression bearing specifically on the pancreatic B cell. In the GK rats, however, the finding of a normal m-GDH activity in splenocytes reveals that, even in an inherited animal model of type 2 diabetes, the deficiency of the mitochondrial enzyme may represent a specific feature of the pancreatic $\mathrm{B}$ cell, rather than a generalized enzymatic defect also found in extra-pancreatic cell types. By analogy, it is quite conceivable that, in some NIDDM patients, an m-GDH deficiency could prevail in the pancreatic B cell despite normal activity of this enzyme in lymphocytes [25].

Up to 1996, no information was available on the m-GDH content in islets of normal and diabetic animals. Hence, no distinction could be made between a defect in the intrinsic catalytic properties of the enzyme, as conceivably attributable to a mutation of m-GDH gene, or an impaired expression of such a gene in the islet cells. The content of immunoreactive m-GDH was directly assessed by Western blotting in islet extracts from control rats, hereditarily diabetic Goto-Kakizaki rats, and rats that were injected with STZ during the neonatal period. For purpose of comparison, the glucokinase content was also measured in the same islet extracts. The results concerned the age, body weight, plasma glucose concentration, plasma insulin concentration, plasma insulin/glucose ratio, islet protein and insulin content. Representative Western blots for $\mathrm{m}-\mathrm{GDH}$ and glutamine from control GK and STZ rats were illustrated. Relative to the corresponding control values, the glucokinase content of pancreatic islets averaged 92.6 $\pm 15.2 \%$ and $50.3 \pm 14.8 \%$ in GK and STZ rats, respectively, whilst the $\mathrm{m}-\mathrm{GDH}$ content of the islets was decreased to $9.1 \pm 4.5 \%$ and $6.8 \pm 1.8 \%$ of corresponding control values in GK and STZ rats, respectively. This study thus indicated that the m-GDH content is severely decreased in islets from both GK and STZ rats. This finding reinforced the view that a defect of this mitochondrial enzyme in islet cells represents a far-from-uncommon feature in animal models of type 2 diabetes and, hence, that it may indeed participate to the alteration of B-cell secretory behavior in this disease [19].

An impaired activity of rat pancreatic islet mitochondrial glycerophosphate dehydrogenase was also observed in protein malnutrition. In rats that received a low protein isocaloric diet (protein content 8 instead of $20 \%$ ) during fetal life and thereafter up to the time of sacrifice at 12 - 13 weeks of age, a low plasma insulin concentration, a decreased insulin content of isolated pancreatic islets, and an impaired secretory response to either D-glucose or the association of L-leucine and L-glutamine coincided, in islet homogenates, with a low activity of the mitochondrial glycerophosphate dehydrogenase and an abnormally high ratio between glutamate-alanine and glutamateaspartate transaminase activities. Opposite enzymatic changes were found in liver extracts of the same rats. No obvious changes in these hormonal, secretory and enzymatic variables were observed when the period of protein deficiency was restricted to fetal life. These findings support the view that, in protein malnutrition, an impaired activity of pancreatic B-cell 
mitochondrial glycerophosphate dehydrogenase contributes, possibly in association with other enzymatic anomalies, to the perturbation of islet function [26].

The thrifty phenotype hypothesis concerning the etiology of type 2 (non-insulin-dependent) diabetes mellitus postulates that poor nutrition in fetal or early infant life is detrimental to the development and function of B cells in the islets of Langerhans. It was, therefore, explored whether protein malnutrition in postnatal and early life may affect the activity of m-GDH in pancreatic islets of adult rats. Female rats were fed a low or normal protein diet and after delivery (day 0 ) housed together with 7 - 8 female pups and given access to a diet containing either 8 or $24 \%(\mathrm{w} / \mathrm{w})$ protein. After weaning (day 8$)$, six young animals were given access to the same two diets up to the end of the 10th week after birth (day 70). Thereafter, all animals were given access to a standard diet containing $21 \%$ $(\mathrm{w} / \mathrm{w})$ protein up to the time of killing by decapitation (day 164). Blood was collected for measurement of plasma glucose and insulin. Three batches of 500 islets each were prepared from the six animals in each group. The protein and insulin contents, and the activity of m-GDH, GlDH, GAD and both alanine and aspartate amino-transferase were measured in the islet homogenates. Liver homogenates prepared from each rat were also examined for their protein content and enzymatic activity. The body weight of the rats given access to the low protein diet was significantly lower than that of control animals from the 18th to 88th day after birth. When the animals were killed, no significant difference was found between the two groups in terms of body weight, plasma glucose and insulin concentrations, islet and liver protein contents. The activity of $\mathrm{m}-\mathrm{GDH}$, as assessed by either a radioisotopic or colorimetric procedure, was lower in the islets of rats fed the low protein diet than in the control animals. Such a difference was not observed in liver extracts. The activity of another mitochondrial enzyme, namely GIDH, was comparable in the two groups of rats, whether in islets or liver extracts. The decreased activity of $\mathrm{m}-\mathrm{GDH}$ in islets of rats fed the low protein diet was apparently not attributable to a decreased contribution of B cells to total islet mass. Thus, neither the insulin content nor the activity of GAD, which is virtually restricted to B cells in the islets, was significantly decreased in the islets of the rats fed the low protein diet. This study thus revealed that protein malnutrition early in life results in a decreased activity of m-GDH in rat pancreatic islets at the adult age. Such an enzymatic change may contribute to the perturbation of pancreatic B-cell function in these animals. In other words, a deficient activity of this mitochondrial enzyme in the pancreatic B cell could represent an essential feature of the thrifty phenotype hypothesis for NIDDM [27].

In the first study concerning [57BL/Ks]- $d b / d b$ mice, in which diabetes mellitus represents an inherited disease, the activity of m-GDH was found to be decreased in islets, but not liver homogenates. The decreased activity of m-GDH contrasted with a normal activity of GIDH and 2-ketoglutarate dehydrogenase in the islets of $d b / d b$ mice. It was proposed that a site-specific defect of FAD-linked glycerophosphate dehydrogenase in the pancreatic B cell might represent a far-fromuncommon cause or contributing factor in the pathogenesis of NIDDM [28].
Likewise, in $f a / f a$ rats, in which inherited diabetes mellitus is associated with obesity, hyperinsulinism and severe insulin resistance, the specific activity of both FAD-linked glycerophosphate dehydrogenase and GIDH were decreased in the islet and liver homogenates prepared from $f a / f a$, as compared to $\mathrm{Fa} / \mathrm{Fa}$ rats, this coinciding with a low ratio between glutamate-oxalacetate and GPT activity in both islet and liver extracts, islet hyperplasia, hyperinsulinemia and hepatic steatosis in the hyperglycemic $f a / f a$ rats. It was speculated that a low activity of FAD-linked glycerophosphate dehydrogenase in the pancreatic B cell may participate to the perturbation of glucose homeostasis in $f a / f a$ rats, like in other models of NIDDM [29].

A decreased activity of m-GDH in pancreatic islets was not observed in certain animal models of diabetes mellitus.

For instance, a high activity of FAD-linked glycerophosphate dehydrogenase as measured by both a radioisotopic and colorimetric procedure was found in pancreatic islets of diabetes Golden spiny mice (Acomys russatus). This coincided with 1) apparently normal intrinsic properties of the islet enzyme, as judged from the ratio in reaction velocities recorded with the colorimetric/radioisotopic procedure, 2) normal to low FAD-linked glycerophosphate dehydrogenase activity in liver and 3) normal GIDH activity in both islet and liver homogenates when comparing the results collected in golden spiny mice and $\mathrm{C} 57 \mathrm{BL} / 6 \mathrm{~J}$ mice. It was concluded that a deficient activity of FAD-linked glycerophosphate dehydrogenase in the pancreatic $B$ cell is not a universal feature of NIDDM [30].

The possible consequences of sustained and severe hyperglycemia, together with the resulting long-term B-cell secretory hyperactivity, upon the activity of islet FAD-linked glycerophosphate dehydrogenase were then investigated in a current rat model of B-cell glucotoxicity, i.e. the infusion for $48 \mathrm{~h}$ of a hypertonic solution of D-glucose. Since an impaired generation of ${ }^{3} \mathrm{HOH}$ from L- $\left[2-{ }^{3} \mathrm{H}\right]$ glycerol-3-phosphate by islet homogenates could conceivably be attributable to an impaired transfer of ${ }^{3} \mathrm{H}$ in the electron transfer chain rather than to an altered generation of $\mathrm{FAD}^{3} \mathrm{H}$ in the reaction catalyzed by the mitochondrial glycerophosphate dehydrogenase, it was considered appropriate to measure the activity of the latter enzyme by a second and independent assay based on the ability of 2-(4-iodophenyl)-3-(4-nitrophenyl)-5-phenyltetrazolium chloride to directly accept electrons from the dehydrogenase. The activity of m-GDH was not decreased in islets prepared from glucose-infused rats, the trend even being towards a slight increase in enzymatic activity. The activity of NADP-GIDH and 2-ketoglutarate dehydrogenase was virtually identical in control and glucose-infused rats. However, as judged from paired comparisons, the activity of GAD was significantly increased in the islets of glucose-infused rats. Since the activity of GAD is decreased in pure islet B cells exposed to STZ, the present results suggest that sustained hyperglycemia may, on the contrary, increase the activity of GAD in pancreatic B cells [31].

In islet homogenates prepared from obese $(o b / o b)$ mice, the activity of FAD-glycerophosphate dehydrogenase, as measured through the generation of either ${ }^{3} \mathrm{HOH}$ from L-[2${ }^{3} \mathrm{H}$ ]glycerol-3-phosphate in the presence of FAD or iodoformazan from iodonitrosotetrazolium, displayed values comparable to those found in lean control mice. In the liver of the obese animals, the results obtained by the colorimetric and 
radioisotopic assays yielded a paired ratio twice higher than in control mice. Although isoforms of the mitochondrial enzyme could be present in variable proportions depending on the cell type and genetic background, the present study suggested that, in $o b / o b$ mice, the increased secretory responsiveness of the B cell to D-glucose coincided with an unaltered activity of FADglycerophosphate dehydrogenase in pancreatic endocrine cells. This contrasted with the situation documented in $d b / d b$ mice, in which an impaired secretory response of the B cell to D-glucose is associated with a decreased activity of FADglycerophosphate dehydrogenase [32].

A further study was conducted in non-obese (NOD) mice and age- and sex-matched control mice. The body weight, plasma glucose concentration, plasma insulin concentration, protein and insulin content of isolated pancreatic islets, were all measured in both control and NOD mice. The absence in the plasma of the latter NOD mice of precipitating anti-insulin antibodies was duly verified. Histological data concerned mainly the mononuclear cell infiltration of the islets present in about $25 \%$ of the NOD mice and in none of the control mice. The activity of m-GDH, as well as that of GIDH and both glutamate-oxalacetate and GPTs, was measured in islet, liver and splenocyte homogenates. Despite incipient insulitis and euglycemia, the NOD mice displayed both high islet insulin content and elevated insulinemia. The activity of m-GDH, expressed relative to protein content, was not decreased in the islets of NOD mice, despite the fact that such a specific activity was lower in splenic lymphocytes than islet cells. In liver homogenates, the activity of m-GDH was even higher in NOD than control mice. It was proposed, therefore, that in this model of insulin-dependent diabetes no primary decrease of islet mGDH activity occurs, at variance with the situation prevailing in several animal models of NIDDM [33].

An increased activity of FAD-linked glycerophosphate dehydrogenase was even observed in pancreatic islets of diabetes prone BB rats. The body weight, glycemia, plasma insulin concentration, pancreatic islet protein content, liver and spleen protein content were all comparable in control (BW) and diabetes prone (BB) rats. The m-GDH activity, measured by either a colorimetric or radioisotopic procedure, was twice higher in BB than BW rats. Such was not the case in either liver or spleen homogenates. No obvious difference between $\mathrm{BB}$ and $\mathrm{BW}$ rats was observed, in terms of the activity of either GAD or 2-ketoglutarate dehydrogenase, whether in islet, liver or spleen homogenates. A selective increase of m-GDH activity in pancreatic islets thus prevailed in $\mathrm{BB}$ rats examined before the onset of severe hyperglycemia in this model of autoimmune insulin-dependent diabetes [34].

The question was also raised whether m-GDH may act as antigenic determinant in STZ-induced autoimmune insulitis. CD-1 mice, that had received five daily injections of STZ (45 $\mu \mathrm{g} /$ body wt.), demonstrated pancreatic insulitis, hypoinsulinemia and hyperglycemia from the fifth and 11th day after the last administration of the diabetogenic agent. The protein and insulin content of those islets that could be isolated from STZ-injected mice tended to be lower than that of islets from control mice. A transient decrease in the specific activity of the $\mathrm{m}-\mathrm{GDH}$ to $57 \pm 14 \%$ of control value was observed in the islets 3 - 5 days after STZ administration, whilst the activity of
GIDH and paired ratio for $\mathrm{m}-\mathrm{GDH} / \mathrm{GlDH}$ mRNA were not significantly affected in the islets from STZ-treated mice. In these animals, no proliferic response of splenic T cells to either GAD or $\mathrm{m}-\mathrm{GDH}$ and no circulating antibodies to the two enzymes could be detected. Since antibodies to GAD and m-GDH are not uncommonly found in patients with insulin-dependent diabetes mellitus, the present findings suggested that a chemical cytotoxic aggression to islet B cells, such as that provoked by STZ, may not represent a sufficient and/or frequent feature in the pathogenesis of type 1 diabetes in human subjects [35].

Last, when male adult rats that had been injected with STZ during the neonatal period were given access to acarbose (40 $\mathrm{mg} / 100 \mathrm{~g}$ of food) for $1 \mathrm{month}$, the fluid intake, glycemia, pancreatic islet content in m-GDH and activity of this enzyme in islet homogenates were all improved, but the plasma insulin concentration remained unchanged. Likewise, when the STZ rats were grafted under the renal capsule with 1,000 - 1,200 islets from normal rats, the m-GDH content of pancreatic islets again increased. This now coincided with a significant increase in plasma insulin concentration, but a somewhat lower increment in insulin output, in response to a rise in D-glucose concentration from 2.8 to $16.7 \mathrm{mM}$ during incubation of islets from transplanted rats than in those from untreated STZ rats. By comparison with data obtained in other experimental models of B-cell dysfunction, these findings suggested that sustained hyperglycemia unfavorably affects expression of the $\mathrm{m}-\mathrm{GDH}$ gene in pancreatic islets suffering from a primary alteration of their insulin-secreting cell population [36].

Attention was also paid to the ontogeny of FAD-linked glycerophosphate dehydrogenase in rat pancreatic islets. The activity of m-GDH, GIDH, $\alpha$-ketoglutarate dehydrogenase, GPT and GOT were measured in islet and liver homogenates from fetal, neonatal, adult male, adult female, pregnant and lactating rats. Either parallel or dissociated ontogenic changes were observed in islet and liver homogenates. The activity of islet m-GDH was slightly, albeit not significantly, lower in neonates than in adult rats, comparable in male and female adult animals, unaffected by pregnancy, and increased during lactation. It was much higher in fetal or adult islets cultured for 7 days than in freshly isolated islets from adult rats. In cultured islets from adult rats, the increase in m-GDH activity coincided with a dramatic decrease of GPT activity, a situation in mirror image of that found in several animal models of NIDDM. The intrinsic properties of $\mathrm{m}-\mathrm{GDH}$, as judged by comparison of the measurements made by either a radioisotopic or a colorimetric procedure were not identical in islet and liver homogenates and differed between fetal and adult islets, suggesting the existence of distinct iso-enzymes. These findings were considered to illustrate adaptive changes of islet enzymes, with exclusive or partial mitochondrial location, in ontogenic situations characterized by a remodeling of fuel homeostasis [37].

\section{Investigations in Human Subjects}

In considering the extension of these investigations to human subjects, it was judged virtually not possible to have access 
to fresh pancreatic samples obtained from a large number of diabetic subjects. In the light of the study conducted in mice or rats, it was conceivable, however, that in some of the diabetic patients, an m-GDH deficiency would not be restricted to islet $\mathrm{B}$ cells, at variance with the situation prevailing in the GK rats or $d b / d b$ mice. These considerations led us to assess in type 2 diabetic and control subjects, the activity of m-GDH in lymphocytes isolated from $10 \mathrm{~mL}$ blood samples and then grown in vitro in order to obtain sufficient $\mathrm{T}$ cells for the enzyme measurements. The mean results indicated that an abnormally low activity of $\mathrm{m}-\mathrm{GDH}$ in $\mathrm{T}$ lymphocytes prevailed in 12 out of 32 patients with type 2 diabetes, whilst a comparable decrease, as assessed by both the colorimetric and radioisotopic procedures, was only found once in 26 other subjects including 11 healthy volunteers, nine non-diabetic patients, five subjects with type 1 diabetes and one patient with diabetes secondary to pancreatectomy for ethylic pancreatitis. Interestingly, in some of the type 2 diabetic subjects, the m-GDH deficiency coincided with an abnormally high ratio between glutamate-pyruvate and GOT activities. Moreover, in two out of five patients with type 1 diabetes, an abnormally low m-GDH activity was found in the radioisotopic procedure, but not in the colorimetric assay. Such a dissociated behavior of m-GDH was only observed in one type 2 diabetic subjects [38].

The major aim of the next study was to explore whether a comparable deficiency of m-GDH activity prevails in patients with insulin-dependent diabetes mellitus. No significant difference between nine control subjects and nine type 1 diabetic patients was observed in terms of the protein content of T lymphocytes or their m-GDH activity, as assessed by either the colorimetric or radioisotopic procedure. Likewise, the activity of GIDH and both glutamate-oxalacetate and GPTs did not differ significantly between control and diabetic subjects. Nevertheless, in two of these patients with type 1 diabetes, the ratio between colorimetric/radiositopic procedure yielded values in excess of those encountered in normal subjects, as already noticed in the former study [39].

Only restricted information was available on the activity of FAD-linked glycerophosphate dehydrogenase in pancreatic islets from human subjects. A comparison between enzymatic, metabolic and secretory patterns in human islets isolated from 11 non-diabetic cadaveric organ donors and three type 2 diabetic subjects indicated that the activity of FAD-glycerophosphate dehydrogenase, but not that of either GIDH, GOT or GPT, was lower in the NIDDM patients than in control subjects. The utilization of D- $\left[5-{ }^{3} \mathrm{H}\right]$ glucose, oxidation of D-[6$\left.{ }^{14} \mathrm{C}\right]$ glucose and release of insulin evoked by D-glucose were all lower in type 2 diabetic patients than in control subjects. The secretory response to the combination of L-leucine and L-glutamine appeared less severely affected. It was proposed that islets from type 2 diabetic patients may thus display enzymatic, metabolic and secretory anomalies similar to those often observed in animal models of type 2 diabetes, including a deficiency of beta-cell FAD glycerophosphate dehydrogenase, the key enzyme of the glycerol phosphate shuttle [40].

Considering that in some diabetic subjects, the activity of $\mathrm{m}-\mathrm{GDH}$ in lymphocytes appears more severely altered when the assay is made by a radioisotopic procedure based on the conversion of L-[2- $\left.{ }^{3} \mathrm{H}\right]$ glycero-3-phosphate to ${ }^{3} \mathrm{HOH}$, rather than by a colorimetric technique based on the generation of iodoformozan from 2-(4-iodophenyl)-3-(4-nitrophenol)-5-phenyltetrazolium and, hence, since the former radioisotopic procedure depends on the integrity of the mitochondrial electron transport chain, such a dissociated behavior could conceivably reflect a site-specific enzymatic defect in oxidative phosphorylation. A further study of $\mathrm{m}-\mathrm{GDH}$ activity was conducted, therefore, in lymphocytes of patients with mitochondrial mutation of the tRNA ${ }^{\text {Leu(UUR) }}$ mitochondrial gene, otherwise responsible for the MELAS (mitochondrial myopathy, encephalopathy, lactic acidosis and stroke-like episodes) syndrome. The six patients with tRNA ${ }^{\text {Leu(UUR) }}$ gene mutation included one male and five females. Three of these subjects were normoglycemic, one of them displayed impaired glucose tolerance and the last two subjects were diabetic. The paired ratio between reaction velocities in the radioisotopic/colorimetric assay was virtually identical in eight control subjects and those affected by the tRNA ${ }^{\text {Leu(UUR) }}$ mutation [41]. The oxidation of D- $\left[1-{ }^{14} \mathrm{C}\right]$ glucose, D-[2- $\left.{ }^{14} \mathrm{C}\right]$ glucose and D-[6- $\left.{ }^{14} \mathrm{C}\right]$ glucose also occurred at a normal rate in intact lymphocytes from subjects affected by the same mitochondrial gene mutation [42]. These findings suggested that an altered ratio in reaction velocity in the radioisotopic/colorimetric assay for m-GDH activity, as occasionally observed in lymphocytes and even pancreatic islets of diabetic patients, is more likely to reflect a defect in the intrinsic properties of $\mathrm{m}-\mathrm{GDH}$ than an altered transfer of ${ }^{3} \mathrm{H}$ from $\mathrm{FAD}^{3} \mathrm{H}$ to ${ }^{3} \mathrm{HOH}$, as could conceivably result from an enzymatic deficiency in the electron transport chain.

The view that an inherited or acquired genomic defect of $\mathrm{m}-\mathrm{GDH}$ in lymphocytes, and possibly in pancreatic islet B cells, may participate in the pathogenesis of NIDDM was further supported by a study of m-GDH, GIDH, GPT and GOT activity in purified populations of $\mathrm{CD}^{+}$lymphocytes from 55 control subjects, 62 type 2 diabetics and 50 non-diabetic relatives of the latter patients. As judged from these measurements and relative to the paired value for GIDH, the incidence of abnormally low m-GDH activity was significantly higher in type 2 diabetes than in control subjects. Moreover, the paired ratio in reaction velocity between the colorimetric and radioisotopic assay of m-GDH was abnormally high in patients with low m-GDH activity. Low m-GDH activity often coincided with increased GPT activity in plasma or high GTP/GOT ratio in lymphocytes. No obvious clustering of these anomalies was found in the relatives of diabetic patients [43].

An abnormally low activity of $\mathrm{m}-\mathrm{GDH}$ relative to the paired measurement of GIDH was also found in $\mathrm{CD}^{+}$lymphocytes from four out of 14 mothers with gestational diabetes mellitus, but none of 36 control mothers. The low m-GDH activity coincided with an abnormally high incidence of familial history for NIDDM. These findings were considered as compatible with the view that an inherited or acquired defect of $\mathrm{m}$-GDH may participate to the pathogenesis of pancreatic islet B-cell dysfunction in a subgroup of patients with gestational diabetes [44].

The cDNA fragment coding for the FAD-, glycerophosphate- and calcium-binding domains of m-GDH were synthetized using RNA extracted from freshly isolated pancreatic islets of a normal subject and two NIDDM patients. Single strand conformational polymorphism analysis of the PCR 
products yielded the same mobility as control cDNA-probes. Likewise, the nucleotide sequence and corresponding amino acid sequence were identical to the normal gene bank sequence. These findings argued against the presence, in pancreatic islets, of an m-GDH isoform distinct from that previously characterized in extra-pancreatic organs [45].

A polyclonal antibody, raised against a recombinant $\mathrm{m}$ GDH fragment product, was eventually developed so that it could be used for the immunodetection of m-GDH. Briefly, total RNA was isolated from rat pancreatic islets and used in the synthesis of cDNA. Specific primers were designed that corresponded to the FAD binding domain of $\mathrm{m}-\mathrm{GDH}$. The PCR product was purified and cloned into an appropriate expression vector used for transformation of Escherichia coli cells. The fusion protein was extracted from the transformed cells, further purified, and used for immunization of rabbits. The antibody recognized a single band of $72 \mathrm{kDa}$ in rat islets and testis. The recombinant $\mathrm{m}-\mathrm{GDH}$ product was also recognized as a single band with the expected $65 \mathrm{kDA}$ reference. An ELISA procedure was designed for detection of antibodies against the recombinant fragment product. The availability of the m-GDH antibody opened the way to a number of further applications such as immunocytochemistry and m-GDH quantification in biological material [46].

A first identified case of mutation in the calcium-binding domain of the m-GDH gene in a patient with type 2 diabetes and his glucose-intolerant half-sister was reported in 1997. Single strand conformation polymorphism analysis indeed revealed an abnormal mobility of the ${ }^{32} \mathrm{P}$-labelled polymerase chain reaction product in these two subjects. The corresponding base pair mutations and amino acid changes were also documented. In the diabetic proband, the relative extent of the $\mathrm{Ca}^{2+}$-induced activation of $\mathrm{m}-\mathrm{GDH}$ in $\mathrm{CD}^{+} \mathrm{T}$ lymphocytes was lower than in his brother with a normal m-GDH gene [47].

A further study then revealed that autoantibodies against $\mathrm{m}-\mathrm{GDH}$ are not uncommonly found in patients with IDDM examined at the onset of the disease. Antibodies reacting with a recombinant $\mathrm{m}-\mathrm{GDH}$ fragment product were observed in the serum of four out of 15 type 1 diabetes, but in none of 15 control subjects. Antibodies against m-GDH were also found in four out of 12 patients with autoimmune thyroiditis. These findings revealed that $\mathrm{m}-\mathrm{GDH}$ may act as an antigenic determinant in patients with IDDM or other autoimmune diseases [48].

Using an ELISA procedure for the measurement of mGDH antibodies in both IDDM and NIDDM patients, positive readings, exceeding the upper limit of the normal range, were recorded in seven out of 12 non-diabetic subjects of the same age. The study conducted in 41 NIDDM patients and 15 control subjects of similar age indicated that the incidence of m-GDH positive cases was not significantly different in the diabetic (4/41) and control (1/15) groups, the measurements of optical density in the positive cases barely exceeding the upper limit of the normal range. These findings suggested that the mitochondrial enzyme m-GDH often acts as an antigenic determinant in IDDM, but not in NIDDM patients [49].

A dexamethasone-induced change in FAD-glycerophosphate dehydrogenase mRNA, content and activity, coinciding with changes in the insulin secretory response to D-glucose, was observed in human pancreatic islets cultured for $63 \mathrm{~h}$ at 2.8 or $16.7 \mathrm{mM}$ D-glucose in the presence of $1.0-10.0 \mu \mathrm{M}$ dexamethasone. Thus, the corticosteroid caused a concentration-related decrease in the m-GDH mRNA content of the islets, and decreased both the m-GDH content of the islets and the catalytic activity of the enzyme in islet homogenates. A dual effect of a low concentration of dexamethasone $(10 \mathrm{nM})$ upon the insulin secretory responsiveness of human islets to D-glucose, independently of any significant change of m-GDH gene expression, was also observed. It was proposed that such a dual action may account, in part at least, for both the wellknown increase in insulin output found in hypercorticism and more recently discovered unfavorable direct effect of corticosteroid hormones on the secretory activity of islet B cells [50].

Last, site-directed mutations of the m-GDH gene were found to impair the mitochondrial anchoring of the enzyme in transfected COS-7 cells [51]. Even well preserved mitochondrial anchoring of a site-directed m-GDH mutant, a catalytic defect of the enzyme was eventually observed in the transfected COS-7 cells [52].

As our knowledge on the present issue progressed, it became the matter of several review articles [53-62].

In NIDDM subjects, a possible molecular determinant of the impaired secretory response of insulin-producing cells to glucose, i.e. the decrease in m-GDH activity has, up to now, apparently received relatively little attention. One of the major aims of the present review is to encourage further investigation on the activity of $\mathrm{m}-\mathrm{GDH}$ in pancreatic islets of NIDDM human subjects.

\section{Funding}

This work was not supported by any funding.

\section{Disclosure}

The author has nothing to declare.

\section{References}

1. Malaisse WJ. Alteration of pancreatic B-cell D-glucose metabolism in type 2 diabetes: the G quintet. Endocrinologia. 1993;40:309-313.

2. Gomis R, Novials A, Coves MJ, Casamitjana R, Malaisse WJ. Suppression by insulin treatment of glucose-induced inhibition of insulin release in non-insulin-dependent diabetics. Diabetes Res Clin Pract. 1989;6(3):191-198.

3. Rovira A, Garrote FJ, Valverde I, Malaisse WJ. Anomeric specificity of glucose-induced insulin release in normal and diabetic subjects. Diabetes Res. 1987;5(3):119-124.

4. Furnsinn C, Komjati M, Madsen OD, Schneider B, Waldhausl W. Histochemical changes in pancreatic islets obtained from obese Zucker rats (fa/fa) on a diabetogenic diet. No evidence for non-enzymatic protein glycation in endocrine cells. Acta Endocrinol (Copenh). 
1993;129(1):46-53.

5. Sener A, Malaisse WJ. Stimulation by D-glucose of mitochondrial oxidative events in islet cells. Biochem J. 1987;246(1):89-95.

6. De Vos A, Schuit FC, Malaisse WJ. Preferential stimulation by glucose of its oxidation relative to glycolysis in purified insulin-producing cells. Biochem Int. 1991;24(1):117-121.

7. Ramirez R, Rasschaert J, Sener A, Malaisse WJ. The coupling of metabolic to secretory events in pancreatic islets. Glucose-induced changes in mitochondrial redox state. Biochim Biophys Acta. 1996;1273(3):263-267.

8. Sener A, Malaisse WJ. Hexose metabolism in pancreatic islets. $\mathrm{Ca}(2+)$-dependent activation of the glycerol phosphate shuttle by nutrient secretagogues. J Biol Chem. 1992;267(19):13251-13256.

9. Giroix M-H, Rasschaert J, Bailbe D, Leclercq-Meyer V, Sener A, Portha B, Malaisse WJ. Impairment of the glycerol phosphate shuttle in islets from rats with diabetes induced by neonatal streptozotocin. Diabetes. 1991;40:227232.

10. Giroix MH, Baetens D, Rasschaert J, Leclercq-Meyer V, Sener A, Portha B, Malaisse WJ. Enzymic and metabolic anomalies in islets of diabetic rats: relationship to B cell mass. Endocrinology. 1992;130(5):2634-2640.

11. Sener A, Giroix MH, Malaisse-Lagae F, Bailbe D, Leclercq-Meyer V, Portha B, Malaisse WJ. Metabolic response to nonglucidic nutrient secretagogues and enzymatic activities in pancreatic islets of adult rats after neonatal streptozotocin administration. Biochem Med Metab Biol. 1993;49(2):182-199.

12. Portha B, Giroix MH, Serradas P, Welsh N, Hellerstrom C, Sener A, Malaisse WJ. Insulin production and glucose metabolism in isolated pancreatic islets of rats with NIDDM. Diabetes. 1988;37(9):1226-1233.

13. Malaisse WJ, Giroix MH, Zahner D, Marynissen G, Sener A, Portha B. Neonatal streptozotocin injection: a model of glucotoxicity? Metabolism. 1991;40(10):1101-1105.

14. Rasschaert J, Malaisse WJ. Streptozotocin-induced suppression of FAD-linked glycerophosphate dehydrogenase in pancreatic islets of adult rats. Biochem Int. 1991;23(4):707-714.

15. Rasschaert J, Malaisse WJ. Streptozotocin-induced FADglycerophosphate dehydrogenase suppression in pancreatic islets. Relationship with the severity and duration of hyperglycaemia and resistance to insulin or riboflavin treatment. Acta Diabetol. 1993;30(1):6-10.

16. Ostenson CG, Abdel-Halim SM, Rasschaert J, MalaisseLagae F, Meuris S, Sener A, Efendic S, et al. Deficient activity of FAD-linked glycerophosphate dehydrogenase in islets of GK rats. Diabetologia. 1993;36(8):722-726.

17. Giroix MH, Sener A, Portha B, Malaisse WJ. Preferential alteration of oxidative relative to total glycolysis in pancreatic islets of two rat models of inherited or acquired type 2 (non-insulin-dependent) diabetes mellitus. Diabetologia. 1993;36(4):305-309.

18. Giroix MH, Sener A, Bailbe D, Leclercq-Meyer V, Portha B, Malaisse WJ. Metabolic, ionic, and secretory response to D-glucose in islets from rats with acquired or inherited non-insulin-dependent diabetes. Biochem Med Metab Biol. 1993;50(3):301-321.

19. Fabregat ME, Novials A, Giroix MH, Sener A, Gomis R, Malaisse WJ. Pancreatic islet mitochondrial glycerophosphate dehydrogenase deficiency in two animal models of non-insulin-dependent diabetes mellitus. Biochem Biophys Res Commun. 1996;220(3):1020-1023.

20. Sener A, Malaisse-Lagae F, Ulusoy S, Leclercq-Meyer V, Malaisse WJ. Contrasting secretory behaviour of pancreatic islets from old rats in two models of non-insulindependent diabetes. Diab Res. 1996;31:67-76.

21. Rasschaert J, Eizirik DL, Malaisse WJ. Long term in vitro effects of streptozotocin, interleukin-1, and high glucose concentration on the activity of mitochondrial dehydrogenases and the secretion of insulin in pancreatic islets. Endocrinology. 1992;130(6):3522-3528.

22. Rasschaert J, Ling Z, Malaisse WJ. Effect of streptozotocin and nicotinamide upon FAD-glycerophosphate dehydrogenase activity and insulin release in purified pancreatic B-cells. Mol Cell Biochem. 1993;120(2):135-140.

23. Rasschaert J, Malaisse WJ. Intrinsic properties of FADlinked glycerophosphate dehydrogenase in islets from normal and streptozotocin-induced diabetic rats. Diabetes Res. 1992;20(1):13-20.

24. Rasschaert J, Malaisse WJ. Activity of cytosolic and mitochondrial enzymes participating in nutrient catabolism of normal and tumoral islet cells. Int J Biochem Cell Biol. 1995;27(2):195-200.

25. Anak O, Giroix M-H, Sener A, Malaisse WJ. FAD-glycerophosphate dehydrogenase activity in splenocytes of rats with acquired or inherited diabetes mellitus. Med Sci Res. 1993;21:565-566.

26. Rasschaert J, Reusens B, Dahri S, Sener A, Remacle C, Hoet JJ, Malaisse WJ. Impaired activity of rat pancreatic islet mitochondrial glycerophosphate dehydrogenase in protein malnutrition. Endocrinology. 1995;136(6):26312634.

27. Sener A, Malaisse-Lagae F, Malaisse WJ. Decreased activity of mitochondrial glycerophosphate dehydrogenase in islets of rats fed a low protein diet. Med Sci Res. 1993;21:625-626.

28. Sener A, Herberg L, Malaisse WJ. FAD-linked glycerophosphate dehydrogenase deficiency in pancreatic islets of mice with hereditary diabetes. FEBS Lett. 1993;316(3):224-227.

29. Rasschaert J, Malaisse-Lagae F, Sener A, Leclercq-Meyer V, Herberg L, Malaisse WJ. Impaired FAD-glycerophosphate dehydrogenase activity in islet and liver homogenates of fa/fa rats. Mol Cell Biochem. 1994;135(2):137141.

30. Sener A, Malaisse-Lagae F, Anak O, Rozenfeld F, Malaisse WJ. High activity of FAD-linked glycerophosphate dehydrogenase in pancreatic islets of diabetic golden spiny mice. Diab Res. 1992;21:11-17.

31. Sener A, Malaisse-Lagae F, Malaisse WJ. Pancreatic islet FAD-linked glycerophosphate dehydrogenase activity in a model of B-cell glucotoxicity. Med Sci Res. 1992;20:701-703.

32. Sener A, Anak O, Leclercq-Meyer V, Herberg L, Malaisse 
WJ. FAD-glycerophosphate dehydrogenase activity in pancreatic islets and liver of ob/ob mice. Biochem Mol Biol Int. 1993;30(3):397-402.

33. Anak O, Malaisse-Lagae F, Leclercq-Meyer V, Sener A, Malaisse WJ. FAD-linked glycerophosphate dehydrogenase activity in islets, liver, and splenocytes of NOD mice. Biochem Med Metab Biol. 1993;50(1):67-74.

34. Rasschaert J, Malaisse WJ. Increased activity of FADlinked glycerophosphate dehydrogenase in pancreatic islets of BB rats. Biochem Mol Biol Int. 1993;29(2):369374.

35. Delvaux A, Rasschaert J, Malaisse WJ. Is rnitochondrial FAD-glycerophosphate dehydrogenase an antigenic determinant in streptozotocin-induced autoimmune insulitis? Diab Res. 1998;33:139-148.

36. Fabregat ME, Fernandez-Alvarez J, Franco C, Corominola H, Mas E, Malaisse WJ, Gomis R. Acarbose treatment or islet transplantation increase FAD-glycerophosphate dehydrogenase content in islets of diabetic rats. Med Sci Res. 1999;27:393-396.

37. Rasschaert J, Malaisse WJ, Tanigawa K. Ontogeny of FAD-linked glycerophosphate dehydrogenase in rat pancreatic islets. Reprod Fertil Dev. 1996;8(3):443-448.

38. Malaisse WJ, Malaisse-Lagae F, Kukel S, Reinhold U, Sener A. Could non-insulin-dependent diabetes mellitus be attributable to a deficiency of FAD-linked glycerophosphate dehydrogenase? Biochem Med Metab Biol. 1993;50(2):226-232.

39. Malaisse WJ, Zahner D, Malaisse-Lagae F, Sener A. Absence of FAD-glycerophosphate dehydrogenase deficiency in lymphocytes of insulin-dependent diabetic subjects. Med Sci Res. 1993;21:269-270.

40. Fernandez-Alvarez J, Conget I, Rasschaert J, Sener A, Gomis R, Malaisse WJ. Enzymatic, metabolic and secretory patterns in human islets of type 2 (non-insulin-dependent) diabetic patients. Diabetologia. 1994;37(2):177181.

41. Rasschaert J, Pueyo ME, Velho G, Froguel P, Malaisse WJ. FAD-glycerophosphate dehydrogenase activity in lymphocytes of patients with mitochondrial mutation of the tRNALeu(UUR) gene. Med Sci Res. 1995;23:143144.

42. Malaisse WJ, Pueyo ME, Nadi AB, Malaisse-Lagae F, Froguel P, Velho G. D-glucose metabolism in lymphocytes of patients with mitochondrial point mutation of the tRNALeu(UUR) gene. Biochem Mol Med. 1995;54(2):91-95.

43. Vidal J, Rasschaert J, Sener A, Gomis R, Malaisse WJ. FAD-glycerophosphate dehydrogenase activity in lymphocytes of type-2 diabetic patients and their relatives. Diabetes Res Clin Pract. 1996;31(1-3):17-25.

44. Vidal J, Corominola H, Cardona F, Levy I, Cararach V, Gomis R, Malaisse WJ. Low mitochondrial glycerophosphate dehydrogenase activity in lymphocytes of women with gestational diabetes. Horm Metab Res. 1997;29(2):60-62.

45. Novials A, Franco C, Malaisse WJ, Gomis R. Nucleotide sequence of cDNA fragments coding for the FAD,glycerophosphate- and calcium-binding domains of human islet mitochondrial glycerophosphate dehydrogenase. Biochem Mol Biol Int. 1997;42(6):1125-1130.

46. Novials A, Fabregat ME, Benito C, Fernandez-Alvarez J, Gallart T, Malaisse WJ, Gomis R. Immunodetection of mitochondrial glycerophosphate dehydrogenase $(\mathrm{mGDH})$ by a polyclonal antibody raised against a recombinant mGDH fragment product. Biochem Mol Med. 1996;59(2):187-191.

47. Novials A, Vidal J, Franco C, Ribera F, Sener A, Malaisse WJ, Gomis R. Mutation in the calcium-binding domain of the mitochondrial glycerophosphate dehydrogenase gene in a family of diabetic subjects. Biochem Biophys Res Commun. 1997;231(3):570-572.

48. Fabregat ME, Gasa R, Rodriguez C, Novials A, Gallart T, Malaisse WJ, Gomis R. Autoantibodies against mitochondrial glycerophosphate dehydrogenase in patients with IDDM. Diabetes Res Clin Pract. 1997;38(2):115121.

49. Fabregat ME, Benito C, Gudayol M, Vidal J, Gallart T, Malaisse WJ, Gomis R. Enzyme-linked immunosorbent assay of autoantibodies against mitochondrial glycerophosphate dehydrogenase in insulin-dependent and noninsulin-dependent diabetic subjects. Biochem Mol Med. 1997;62(2):172-177.

50. Fabregat ME, Fernandez-Alvarez J, Franco C, Malaisse WJ, Gomis R. Dexamethasone-induced changes in FADglycerophosphate dehydrogenase mRNA, content and activity, and insulin release in human pancreatic islets. Diabetes Nutr Metab. 1999;12(6):388-393.

51. Fabregat ME, Usac EF, Franco C, Enrich C, Malaisse WJ, Gomis R. Site-directed mutations of the FAD-linked glycerophosphate dehydrogenase gene impairs the mitochondrial anchoring of the enzyme in transfected COS-7 cells. Biochem Biophys Res Commun. 1998;252(1):173177.

52. Gudayol M, Fabregat ME, Rasschaert J, Sener A, Malaisse WJ, Gomis R. Site-directed mutations in the FAD-binding domain of glycerophosphate dehydrogenase: catalytic defects with preserved mitochondrial anchoring of the enzyme in transfected COS-7 cells. Mol Genet Metab. 2002;75(2):168-173.

53. Malaisse WJ, Rasschaert J. [Insular modifications in glycerophosphate dehydrogenase in diabetes]. Bull Mem Acad R Med Belg. 1991;146(1-2):106-110; discussion 111-102.

54. Malaisse WJ. Glucose-sensing by the pancreatic B-cell: the mitochondrial part. Int J Biochem. 1992;24(5):693701 .

55. Malaisse WJ. Aspects physiologiques et pathologiques du metabolisme du glucose dans les ilots pancreatiques. Rev Francaise Endocrinol Clin. 1993;34:231-239.

56. Malaisse WJ. Perturbation of islet metabolism and insulin release in NIDDM. In: Ostenson C-G, Efendic S, Vranic $M$, eds. New Concepts in the Pathogenesis of NIDDM. New York: Plenum Press. 1993:13-23.

57. Malaisse WJ. Is type 2 diabetes due to a deficiency of FAD-linked glycerophosphate dehydrogenase in pancreatic islets? Acta Diabetol. 1993;30(1):1-5.

58. Malaisse WJ. Pancreatic B-cell FAD-glycerophosphate 
dehydrogenase deficiency in non-insulin-dependent diabetes: an up-dated review. In: Flatt PR, Lenzen S, eds. Frontiers of insulin secretion and pancreatic B-cell research. London: Smith-Gordon. 1994:445-452.

59. Malaisse WJ. FAD-linked glycerophosphate dehydrogenase activity in pancreatic islets of diabetic rodents. Lessons from Animal Diabetes. 1995;5:1-9.

60. Malaisse WJ. Non-insulin-dependent diabetes mellitus and islet B-cell mitochondrial glycerophosphate dehydrogenase deficiency. Diabet Med. 1995;12(6):479-481.

61. Malaisse WJ. Regulation, perturbation, and correction of metabolic events in pancreatic islets. Acta Diabetol. 1996;33(3):173-179.

62. Malaisse WJ. Physiology, pathology and pharmacology of insulin secretion: recent acquisitions. Diabetes Metab. 1997;24(Suppl 3):6-15. 